University of Wollongong

Research Online

Faculty of Engineering and Information

Faculty of Engineering and Information

Sciences - Papers: Part A

Sciences

$1-1-2014$

An investigation of interface bonding of bimetallic foils by combined accumulative roll bonding and asymmetric rolling techniques

Hailiang $\mathrm{Yu}$

University of Wollongong, hailiang@uow.edu.au

A Kiet Tieu

University of Wollongong, ktieu@uow.edu.au

Cheng Lu

University of Wollongong, chenglu@uow.edu.au

Ajit R. Godbole

University of Wollongong, agodbole@uow.edu.au

Follow this and additional works at: https://ro.uow.edu.au/eispapers

Part of the Engineering Commons, and the Science and Technology Studies Commons

Research Online is the open access institutional repository for the University of Wollongong. For further information contact the UOW Library: research-pubs@uow.edu.au 


\title{
An investigation of interface bonding of bimetallic foils by combined accumulative roll bonding and asymmetric rolling techniques
}

\begin{abstract}
The bond strength in bimetallic materials is an important material characteristic. In this study, 0.1-mm thick bimetallic foils (AA1050/AA6061) were produced using one pass of accumulative roll bonding followed by three passes of asymmetric rolling (AR). The AR passes were carried out at roll speed ratios of $1.0,1.1,1.2,1.3$, and 1.4 separately. Finite element simulation was used to model the deformation of the bimetallic foils for the various experimental conditions. Particular attention was focused on the bonding of the interface between AA1050 and AA6061 layers in the simulation. The optimization of the roll speed ratio was obtained for improvement of the bond strength of the interface of AA1050/AA6061 bimetallic foils during AR process. In the simulation, the mean equivalent strain at the interface zone between the AA1050 and AA6061 layers was seen to reach a peak value at a roll speed ratio of about 1.2 to 1.3 , which also corresponded to a high quality bond at the interface as observed experimentally.
\end{abstract}

\section{Keywords}

foils, bimetallic, roll, bonding, asymmetric, interface, techniques, investigation, accumulative, combined, rolling

\section{Disciplines \\ Engineering | Science and Technology Studies}

\section{Publication Details}

Yu, H., Tieu, A. Kiet., Lu, C. \& Godbole, A. (2014). An investigation of interface bonding of bimetallic foils by combined accumulative roll bonding and asymmetric rolling techniques. Metallurgical and Materials Transactions A: Physical Metallurgy and Materials Science, 45A (9), 4038-4045. 


\title{
An Investigation of Interface Bonding of Bimetallic Foils by Combined Accumulative Roll Bonding and Asymmetric Rolling Techniques
}

\author{
HAILIANG YU, A. KIET TIEU, CHENG LU, and AJIT GODBOLE \\ The bond strength in bimetallic materials is an important material characteristic. In this study, \\ 0.1-mm thick bimetallic foils (AA1050/AA6061) were produced using one pass of accumulative \\ roll bonding followed by three passes of asymmetric rolling (AR). The AR passes were carried \\ out at roll speed ratios of 1.0,1.1, 1.2, 1.3, and 1.4 separately. Finite element simulation was \\ used to model the deformation of the bimetallic foils for the various experimental conditions. \\ Particular attention was focused on the bonding of the interface between AA1050 and AA6061 \\ layers in the simulation. The optimization of the roll speed ratio was obtained for improvement \\ of the bond strength of the interface of AA1050/AA6061 bimetallic foils during AR process. In \\ the simulation, the mean equivalent strain at the interface zone between the AA1050 and \\ AA6061 layers was seen to reach a peak value at a roll speed ratio of about 1.2 to 1.3 , which also \\ corresponded to a high quality bond at the interface as observed experimentally.
}

DOI: $10.1007 / \mathrm{s} 11661-014-2311-4$

(c) The Minerals, Metals \& Materials Society and ASM International 2014

\section{INTRODUCTION}

Metal laminates have become increasingly popular for engineering applications since they usually possess several desirable properties. As such they are being increasingly used in various fields such as the automotive, aerospace, medical instrumentation, vessel, and electrical industries ${ }^{[1]}$ for example, laminates can be used for manufacturing parts with different "inner" and "outer" characteristics such as corrosion resistance, wear resistance, and thermal and electrical conductivities. Production of the laminates (e.g., using the deep drawing process) calls for combining the desirable properties of different materials in a single component. Atrian and Fereshteh-Saniee ${ }^{[1]}$ studied the behavior of steel/brass laminated sheets in the deep drawing process. Of late, there is a great demand for micro-formed products. The global market for microsystems reached \$25 billion in 2009, and continues to grow due the increasing demand for microtechnical products. Microforming is recognized as an emerging manufacturing process that involves the fabrication of products from ultra-thin foil material with thickness in the range from 0.001 to $0.3 \mathrm{~mm}$. The development of adequate manufacturing facilities that can supply micro-formed parts in large quantities is, therefore, a key factor in the

HAILIANG YU, Vice-Chancellor's Research Fellow, is with the School of Mechanical, Materials \& Mechatronics Engineering, University of Wollongong, Wollongong, NSW 2500, Australia, and also Professor with the School of Mechanical Engineering, Shenyang University, Shenyang 110044, P.R. China. Contact e-mail: yuhailiang1980@tom.com, hailiang@uow.edu.au A. KIET TIEU, Professor, CHENG LU, Associate Professor, and AJIT GODBOLE, Senior Research Fellow, are with the School of Mechanical, Materials \& Mechatronics Engineering, University of Wollongong.

Manuscript submitted August 24, 2013.

Article published online April 23, 2014 successful development of this process. In addition, the strength of the foils should be improved to maintain the structural stability of the microparts with reduction of the foil thickness. Relevant to this need is the development of nanostructured/ultrafine-grained materials, which have shown higher strength compared with coarse-grained materials. Thus, it would be very interesting to investigate the mechanical properties of ultrathin nanostructured/ultrafine-grained bimetallic foils and develop technologies for potential application in micro-forming.

Among the composite material technologies, roll bonding $(\mathrm{RB})$ is an important technique used to produce laminates because the rolling pressure can create a mechanical bond between the metal strip components. ${ }^{[2]}$ Thus, the evolution of microstructure and mechanical properties during the roll bonding process have been studied, using composite sheets or strips of materials such as $\mathrm{Al}, \mathrm{Al} / \mathrm{Mg}, \mathrm{Al} / \mathrm{Cu}, \mathrm{Cu} / \mathrm{Fe}, \mathrm{Cu} / \mathrm{Ag}$, IF steel, etc. $\mathrm{A}$ high-purity $\mathrm{Al}$ alloy and a supersaturated Al-0.3 wt pct Sc alloy were processed by accumulative roll bonding (ARB) to generate $0.5-\mathrm{mm}$ gage sheets consisting of alternating layers of $\mathrm{Al}$ and $\mathrm{Al}(\mathrm{Sc})$ by Quadir et al ${ }^{[3]}$ In these products, the bands in the $\mathrm{Al}(\mathrm{Sc})$ layers were observed to be more refined than those in the Al layers. Su et al. ${ }^{[4]}$ studied the microstructure and mechanical properties of a 1.5-mm-thick AA1050/ AA6061-laminated composite processed by ARB and observed grain refinement in both the AA1050 and AA6061 layers. The AA1050 layer was seen to be coarser and has more equiaxed microstructure than the AA6061 layer after the second ARB pass. Wu et al. ${ }^{[5]}$ studied the microstructure and mechanical properties of an $\mathrm{Mg}$ /Al-laminated composite of 0.5 -mm thickness fabricated by $\mathrm{ARB}$ at $673 \mathrm{~K}\left(400{ }^{\circ} \mathrm{C}\right)$. The tensile strength of the laminated $\mathrm{Mg} / \mathrm{Al}$ composite along both 
directions (along the roll direction and perpendicular to it) increased gradually when subjected to two ARB passes, but decreased after the third ARB pass. Li et $a l^{[6]}$ studied the interfacial microstructure and mechanical properties of a $\mathrm{Cu} / \mathrm{Al}$ clad sheet fabricated using asymmetric roll bonding with a speed ratio of 1.31 and annealing and found that roll bonding with a larger roll speed ratio improves the ultimate tensile strength, elongation, and peeling force of the clad sheet. $\mathrm{Ag} / \mathrm{Cu}$ bimetallic laminates were fabricated by roll bonding and annealing by Zhang et al. ${ }^{[2]}$ who found that some $\mathrm{Cu}$-rich particles precipitated along grain boundaries in the fine grain region and could harden the $\mathrm{Ag}$ strip component slightly. Kamikawa et al. ${ }^{[7]}$ studied the effect of redundant shear strain on the microstructure and texture evolution in a 1-mm-thick IF steel during ARB processing. However, to date, there have been no reports on the production of bimetallic foils thinner than $0.3 \mathrm{~mm}$, using the $\mathrm{ARB}$ technique for microforming.

In recent years, more attention is being paid to nanostructured materials due to their special properties such as high strength, ductility, and corrosion resistance. It is known that simple shear leads to the optimal deformation mode for development of spatial networks of high angle boundaries and fine grains during flow localization under monotonic loading and cross loading. ${ }^{[8,9]}$ Using this approach, different severe plastic deformation (SPD) techniques have been developed, such as equal channel angular pressing (ECAP), high pressure torsion (HPT), ARB, and asymmetric rolling (AR). ECAP is a very promising SPD technique for producing ultrafine-grained materials and has been used to investigate the formation of submicron grain structures in Al alloys deformed to ultra-high plastic strains by Gholinia et al. ${ }^{[10]}$ They pointed out that the most efficient processing route for forming a submicron grain structure is to maintain a constant strain path and that the least effective path is to reverse the shear each alternate cycle by rotating the billet through $180 \mathrm{deg}$. Besides investigations involving physical experiments, the crystal plastic finite element simulation method has also been used to investigate deformation heterogeneity and texture development during ECAP process by Deng et al. ${ }^{[11]}$ The HPT method refers to the processing of metals, where samples are subjected to a compressive force and concurrent torsional strain. HPT followed by annealing has been used to produce ultrafine-grained copper by Schafler and Kerber ${ }^{[12]}$ who found that the subgrain structure vanishes and the strength becomes governed by the recrystallised grain structure that contains many annealing twins due to the progressive annihilation of dislocations. ARB was developed by Saito et al. ${ }^{[13]}$ and is a method in which a stack of metal sheets is repeatedly rolled under a severe reduction ratio, sectioned into two halves, piled again, and re-rolled. Lee et $a l^{[14]}$ studied the role of shear strain on ultra-grain refinement in aluminum during the ARB process. They found that the grain size distribution through the sheet thickness corresponded well with the shear strain distribution and suggested that the role of shear strain in grain refinement should consider the equivalent strain, strain gradient, and strain path. AR is a technique in which sheets are rolled between rolls that are either of different diameters, or rotating at different angular speeds. $\mathrm{Yu}$ et $a .^{[15,16]}$ used asymmetric cryorolling to produce nanostructured aluminum alloys, and found that the grain size undergoes refinement with increasing difference between the upper and lower roll speeds. In the $A R B$ and AR process, shear stresses appear near the interface, with the result that the pinned dislocation segments with edge orientation at the interface became sources of new dislocations and the interface gradually bonds. ${ }^{[17]}$ The AR technique involves rolling with an imposed shear deformation, which should improve the interface bonding in bimetallic sheet/foil production. To the best of the present authors' knowledge, the ECAP and HPT techniques are only suitable for production of small size workpieces in limited quantities. In addition, there have been no reports on the production of laminate materials by the ECAP and HPT techniques.

Recently, Li et al. ${ }^{[18]}$ and Jammaati and Toroghine$\mathrm{jad}^{[19]}$ conducted reviews on the progress of roll bonding process and bond strength, respectively. In their papers, the influence of annealing time, rolling speed, initial strip thickness, rolling direction, friction coefficient, and surface conditions on the bond strength was discussed. However, the AR process was not considered in these reviews. There are a no. of theoretical models that have been developed for the prediction of roll bonding, and are listed in Table I. However, none of these equations have been used to predict the bond strength of bimetallic foils subjected to AR. Li et al. ${ }^{[20]}$ investigated the tensile properties of $\mathrm{Al} / \mathrm{Cu} / \mathrm{Al}$-laminated composites by asymmetric rolling, and found that the interfacial microstructure and intermetallic compounds improved, which the contaminations at interface reduced and interfacial diffusion increased, compared with that by conventional rolling. Yu et al. ${ }^{[21]}$ developed ultrafine-grained bimetallic foils using the ARB and AR techniques, and showed that the bonding quality increased as the no. of rolling passes increased. However, until now, there have been no reports on the investigation of the influence of AR process parameters on interface bond strength.

In this paper, we report an investigation of the bond strength at the interface of AA1050/AA6061 bimetallic foils produced by one ARB pass followed by three AR passes, with various roll speed ratios. The fracture surfaces of the tensile samples were observed by scanning electron microscopy (SEM) and the microstructure around the interface of AA1050/AA6061 by transmission electron microscopy (TEM). The observations were used to analyze bond quality. Finally, equivalent strains at the interface under various rolling conditions were quantitatively analyzed by the finite element method.

\section{EXPERIMENTAL AND THEORETICAL INVESTIGATIONS}

\section{A. Experimental Investigation}

The ARB and AR techniques were combined to produce bimetallic foils. The rolled samples were 1.5 -mm-thick 
Table I. Theoretical Models of Bond Strength in Rolling Process

\begin{tabular}{|c|c|c|}
\hline & Bond Strength Model & Equation No. \\
\hline Vaidyanath et al..$^{[22]}$ & $\sigma_{\mathrm{b}}=\sigma_{0} R_{\mathrm{f}}\left(2-R_{\mathrm{f}}\right)$ & (1) \\
\hline Wright et al. ${ }^{[23]}$ & $\sigma_{\mathrm{b}}=\sigma_{0} H\left(1-\frac{\left(1-R_{\mathrm{f}}\right)^{2}}{\left(1-R_{\mathrm{t}}\right)^{2}}\right)$ & $(2)$ \\
\hline Bay et al..$^{[24]}$ & $\sigma_{\mathrm{b}}=\left(1-\psi^{2}\right) Y\left(P-P_{\mathrm{E}}\right)+\psi^{2} \frac{Y-Y^{\prime}}{1-Y^{\prime}} p$ & (3) \\
\hline Zhang and Bay ${ }^{[25]}$ & $\sigma_{\mathrm{b}}=\psi p_{\mathrm{b}}$ & (4) \\
\hline Madaah-Hosseini and Kokabi ${ }^{[26]}$ & $\sigma_{\mathrm{b}}=\left(\frac{\sqrt{3}}{2}\right)^{n} \frac{\sigma_{0}}{K} \ln \left(\frac{1}{1-R_{\mathrm{f}}}\right)$ & $(5)$ \\
\hline Govindaraj et al..$^{[27]}$ & $\sigma_{\mathrm{b}}=K_{1} \sigma_{0} \exp \left(-\frac{\sqrt{3}}{2} K_{2} \varepsilon_{\mathrm{e}}\right)$ & (6) \\
\hline
\end{tabular}

Table II. Rolling Parameters and Final Thicknesses of the Bimetallic Foils

\begin{tabular}{lccccc}
\hline Ratio of Rolls Speed & 1.0 & 1.1 & 1.2 & 1.3 & 1.4 \\
\hline Final thickness of foils (mm) & 0.12 & 0.11 & 0.12 & 0.11 & 0.10 \\
\hline
\end{tabular}

sheets of annealed commercial aluminum alloys (AA1050 and AA6061). The ARB process was carried out with two pieces of AA1050 and AA6061 sheets. Their interface treated the sheets that were stacked and welded at one end with a spot welding machine. They were rolled with a reduction of 50 pct at $473 \mathrm{~K}\left(200{ }^{\circ} \mathrm{C}\right) .{ }^{[4]}$ The 1.5 -mm-thick composite sheets were subsequently subjected to three AR passes using a multi-function rolling mill with dry friction $^{[15]}$ at different roll speed ratios until the thickness reduced to about $0.1 \mathrm{~mm}$. The rolling mill had $120-\mathrm{mm}$ diameter rolls, independently driven by two $5.5 \mathrm{~kW}$ motors. The final foil thicknesses and the ratios of roll speeds are listed in Table II. The roll in contact with the AA6061 layer rotated at the higher speed.

After rolling, 25-mm gage length and 6-mm gage width tensile samples were prepared in compliance with ASTM D412 standard. Uniaxial tensile tests were conducted with an initial strain rate of $1.0 \times 10^{-3} \mathrm{~s}^{-1}$ on an INSTRON machine operating at constant speed. The morphology of the fractured surface of the bimetallic samples was studied with a Zeiss Auriga field emission scanning electron microscope (FESEM) operating at $20 \mathrm{kV}$, with a working distance of about $15 \mathrm{~mm}$. Secondary electron images for the top down view were recorded at the same magnification for comparison purposes. Subsequently, a Philips CM200 field emission gun transmission electron microscope (FEG/TEM) equipped with a Bruker energy dispersive X-ray (EDAX) spectroscopy system operating at an accelerating voltage of $200 \mathrm{kV}$ was used to investigate the microstructure of the thin-foil specimens from the bimetallic foils fabricated by an FEI xT Nova Nanolab 200 Dual Beam workstation.

\section{B. Finite Element Simulation}

Figure 1 shows a schematic diagram of the AR process used on the ARB-processed AA1050/AA6061

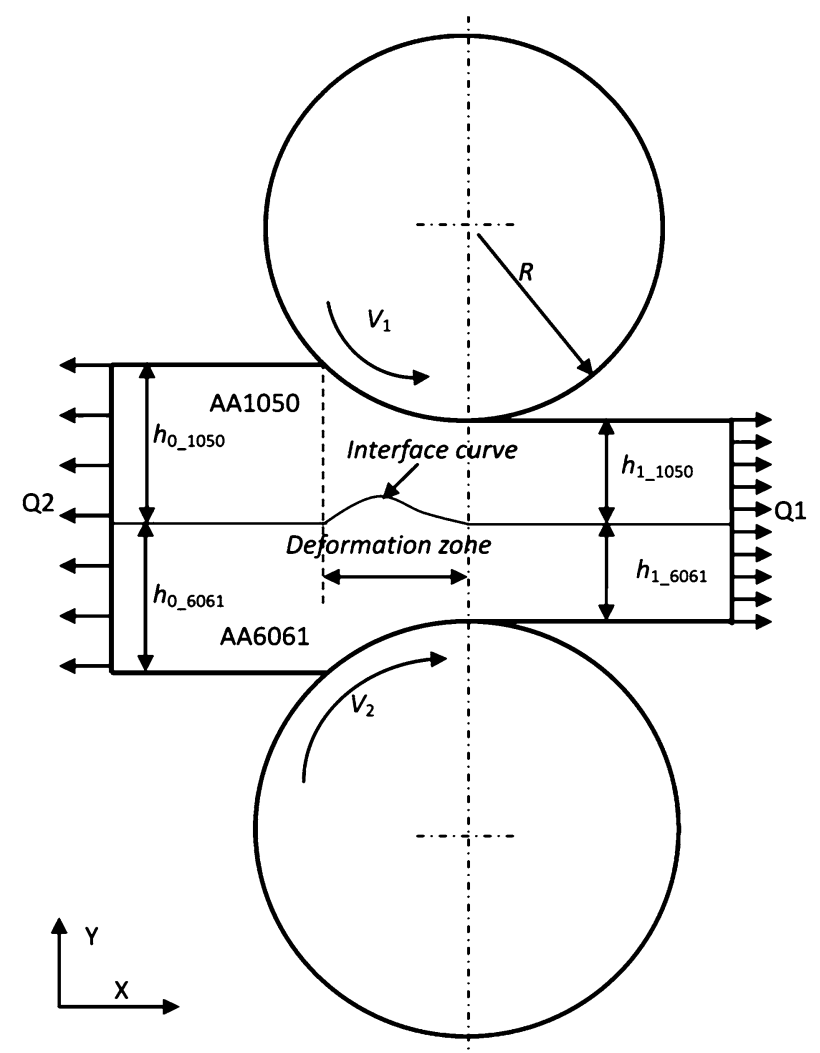

Fig. 1-Illustration of asymmetric rolling process of AA1050/ AA6061 bimetallic foils $\left(V_{2} \geq V_{1}\right)$.

bimetallic foils. The $X$-axis is parallel to the rolling direction, and the $Y$-axis along the strip thickness.

In the two-dimensional $\mathrm{FE}$ model of the AR process set up in LS-DYNA, we assumed that the initial thickness of both layers (AA1050 and AA6061) was $0.75 \mathrm{~mm}$. In the AR process, the reduction ratios chosen were 30 and 40 pct. As in the experiments, the roll speed ratios were set as 1.0, 1.1, 1.2, 1.3, and 1.4. The friction coefficient between the strip and the roll was set as $0.15 .^{[28]}$ During the rolling process, the rolls were regarded as rigid. The isotropic material model was used for the AA1050 and AA6061 layers, and the yield stresses for AA1050 and AA6061 layers were, respectively, 


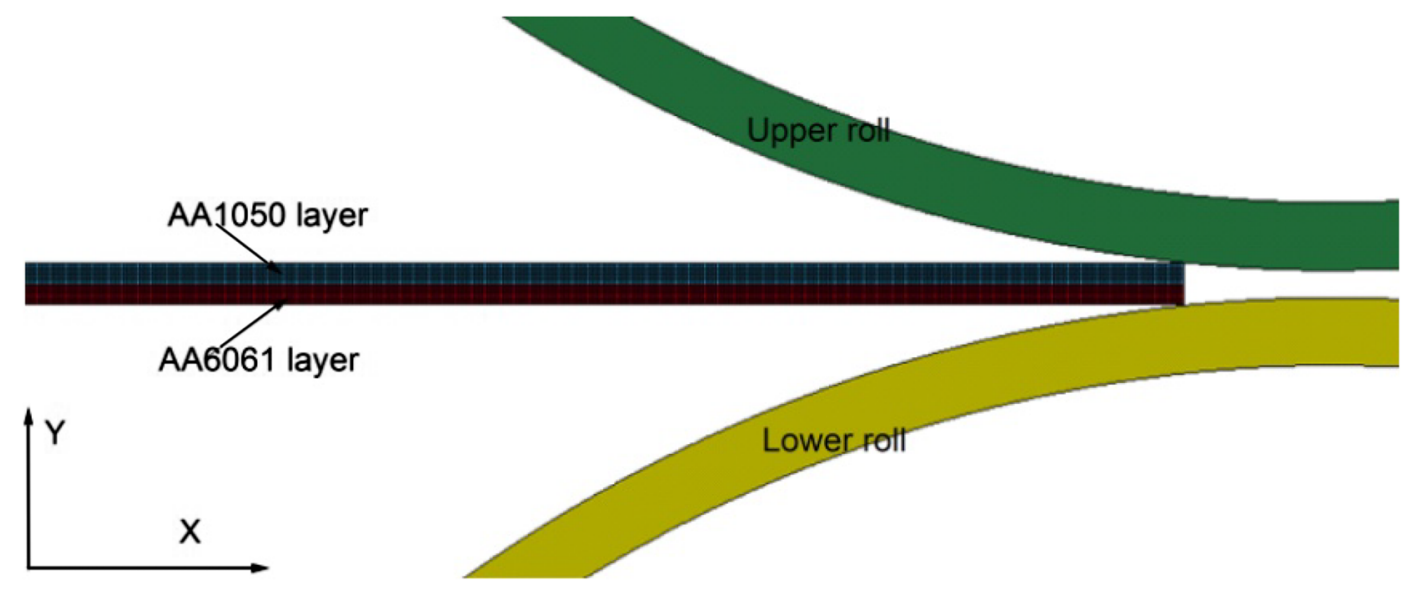

Fig. 2-Geometry and FE meshing of bimetallic foil rolling.

assumed to be 150 and $195 \mathrm{MPa}$, based on the relationship between hardness and yield stress suggested by Lee et al. ${ }^{[29]}$ with the hardness as suggested in Reference 4. Temperature change and sheet width spread were neglected. The geometric models were meshed with square elements and the model contained 10,453 nodes and 8740 elements. The FE meshing of the bimetallic foil for asymmetric rolling is shown in Figure 2. In the rolling process, the rolls rotate with a constant angular speed. The bimetallic foil enters the gap between the rolls with an initial velocity and exits under the action of the friction force.

\section{RESULTS AND DISCUSSION}

It is useful to investigate fracture mechanisms of the interface in the bimetallic foils. The fracture surfaces of the tensile-tested samples were studied by SEM. Figure 3 shows features of the fracture at the interface between the component materials after tensile tests. Figure 3(a) shows the sample after the ARB process, and Figures 3(b) through (f) show the samples after the AR process for the roll speed ratios of 1.0, 1.1, 1.2, 1.3, and 1.4, respectively. Figure 3(a) shows that the interfaces between the AA1050 and AA6061 layers are split in the tensile process. After subsequent AR processing, the interface bond quality is improved greatly, and the interface between AA1050 and AA6061 layers shows decreasing splits, as shown in Figures 3(b) through (f). While some splitting is noticed for roll speed ratios of 1.0 and 1.1, as shown in Figures 3(b) and (c), higher speed ratios of 1.2 and 1.3 produce interfaces essentially free of splits, as shown in Figures 3(d) and (e). However, when the speed ratio increases to 1.4 , the split zone appears again at the interface between the layers, as shown in Figure 3(f).

Figure 4 shows the TEM images of the AA1050/ AA6061 interface in the processed samples. Figure 4(a) shows the ARB-processed sample, and Figures 4(b) through (d) the samples after AR processing with the roll speed ratios of 1.0, 1.2, and 1.4, respectively. As shown in Figure 4(a), there are many elongated residual voids at the interface zone between the AA1050 and AA6061 layers. When the thickness of the bimetallic sheet is further reduced to $0.1 \mathrm{~mm}$ by AR with roll speed ratio 1.2 , the residual voids get eliminated due to further bonding. When the speeds of the upper and lower rolls are the same, there are still some residual voids, as shown in Figure 4(b). When the roll speed ratio is increased to 1.2, the interfaces between the AA1050 and AA6061 layers bond well, and there are no residual voids visible at the interface zone, as shown in Figure 4(c). With further increase of the speed ratio to 1.4 , the interface bond quality deteriorates, as shown in Figure 4(d), in which three residual voids can be seen at the locations marked by the arrows. The TEM results confirm the SEM observations.

The SEM and TEM images show that the bond quality at the AA1050/AA6061 interface improves after AR processing at roll speed ratios of 1.2 and 1.3. However, there are some residual voids at the interface for the other speed ratios outside of this range. Of the equations used for predicting interface bond quality shown in Table I, Eqs. [1], ${ }^{[22]}[2],{ }^{[23]}$ and $[5]^{[26]}$ only consider the final reduction ratio. These equations thus cannot be used to predict the bond quality of bimetallic foils subjected to AR. Recently, Govindaraj et al. ${ }^{[27]}$ have developed a new interface bonding model as shown in Eq. [6] in Table I. In this equation, the bonding quality is related to the equivalent strain at the interface zone during rolling. The higher the equivalent strains at the interface, the better is the interface bond quality, as has been validated through measurement of bond strength by tensile test. ${ }^{[27]}$ Generally, the AR technique results in a higher equivalent strain in samples compared to that by conventional rolling with the same reduction ratio. The equivalent strain $\left(\varepsilon_{\mathrm{e}}\right)$ induced in $\mathrm{AR}$ is given by Cui and Ohori: ${ }^{[30]}$

$$
\varepsilon_{\mathrm{e}}=\frac{2}{\sqrt{3}}\left\{1+\left[\frac{(1-r)^{2}}{r(2-r)} \tan \theta\right]^{2}\right\}^{1 / 2} \ln \frac{1}{1-r}
$$

where

$$
r=1-\left(t_{1} / t_{0}\right)
$$



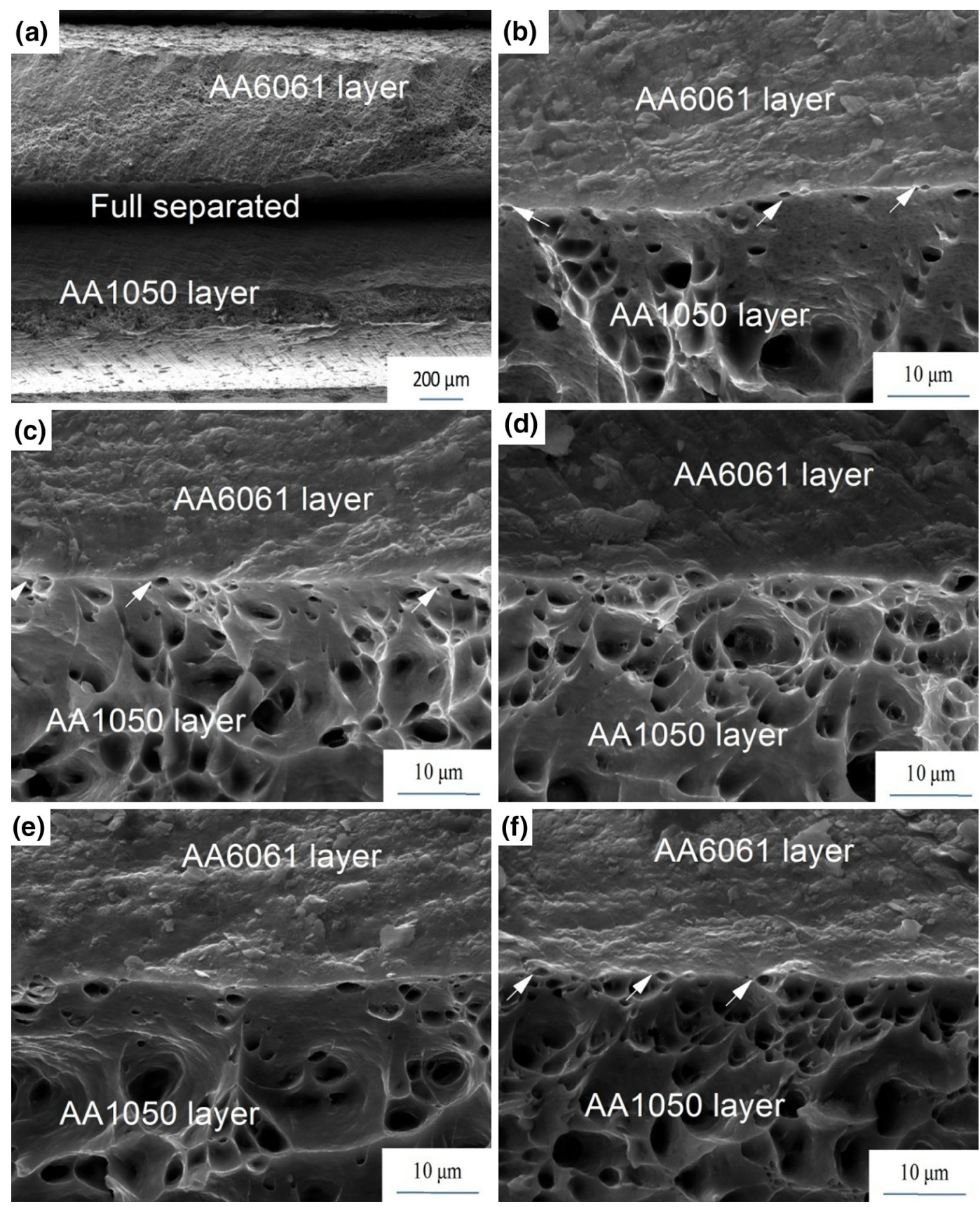

Fig. 3- SEM images of fracture surface around the interface of AA1050/AA6061 after tensile tests $(a)$ ARB-processed sample, $(b)$ through (f) for ratios of rolls speed $1.0,1.1,1.2,1.3$, and 1.4 .

Here $t_{0}$ and $t_{1}$ are the thickness of the sheet before and after $\mathrm{AR}$, and $\theta$ is the apparent shear angle at a given position of the element perpendicular to the surface of the sheet before rolling. The shear angle $\theta$ changes as the AR process parameters change. The relevant process parameters are roll diameter, roll speed, and difference in friction between the upper and lower rolls. It is obvious that the shear angle $\theta$ affects the bond strength between layers in laminate production due to its direct relationship with the equivalent strain. Equation [7] can be used to predict the equivalent strain at the interface zone for a single metallic material. However, it is difficult to calculate the equivalent strain at the interface of bimetallic foils as the yield stresses of the component sheet materials are different.

During AR, the interface of the AA1050/AA6061 can survive a significant fluctuation, as shown in Figure 1. It is obvious that a drastic fluctuation will directly affect interface bonding quality. Figures 5(a) and (b) show the interface location in the rolling deformation zone for a variety of ratios of roll speeds $\left(R_{\mathrm{RS}}\right)$, for reduction ratios of 30 and 40 pct, respectively. The interface curve distribution in the rolling deformation zone has the same trend for the reduction ratio of both 30 and 40 pct, 

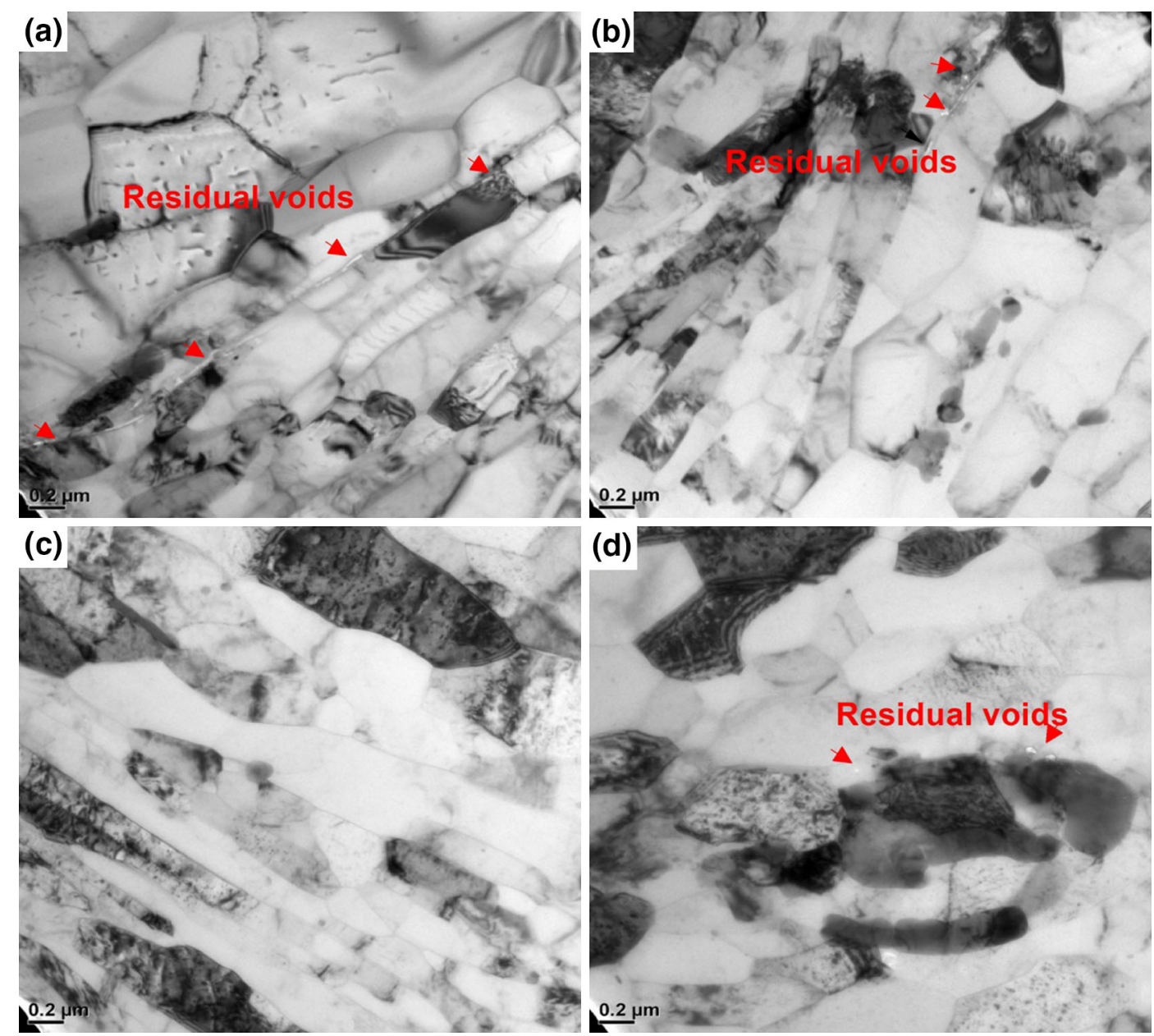

Fig. 4-TEM images of samples around the interface of AA1050/AA6061, $(a)$ ARB-processed sample, $(b)$ through $(d)$ ratios of rolls speed 1.0, 1.2 , and 1.4 .

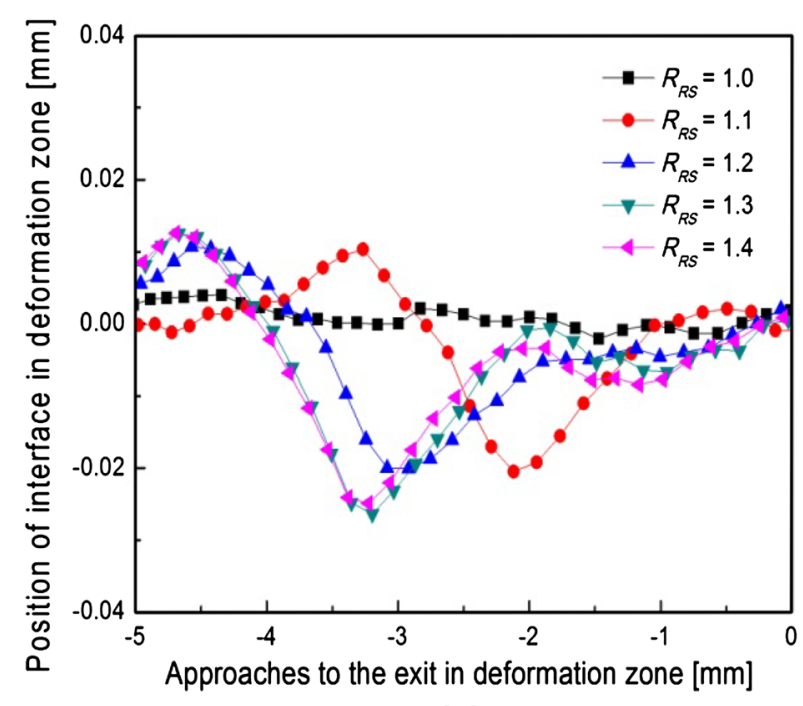

(a)

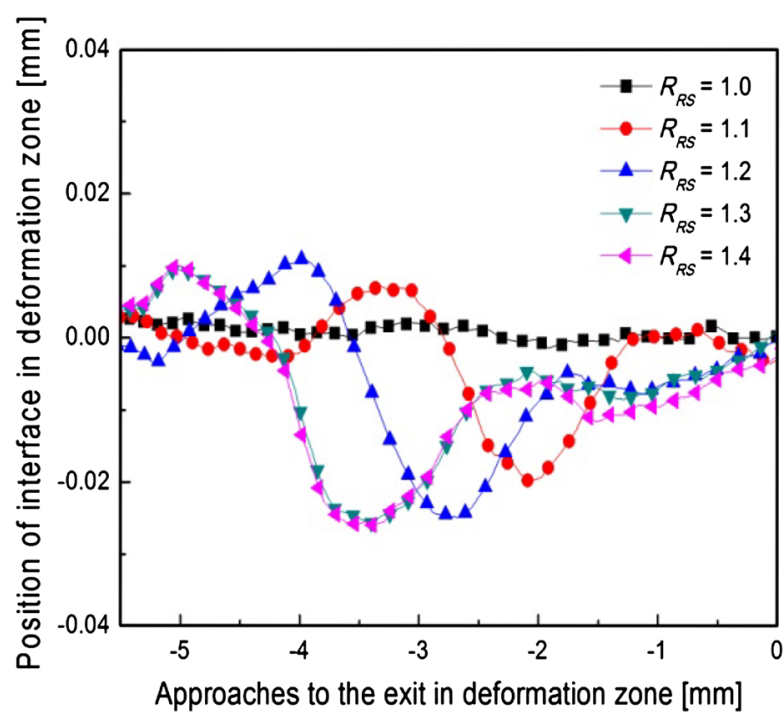

(b)

Fig. 5-Interface curve in the rolling deformation zone under various speed ratios of upper and lower rolls, $(a)$ reduction ratio 30 pct, $(b)$ reduction ratio 40 pct. 


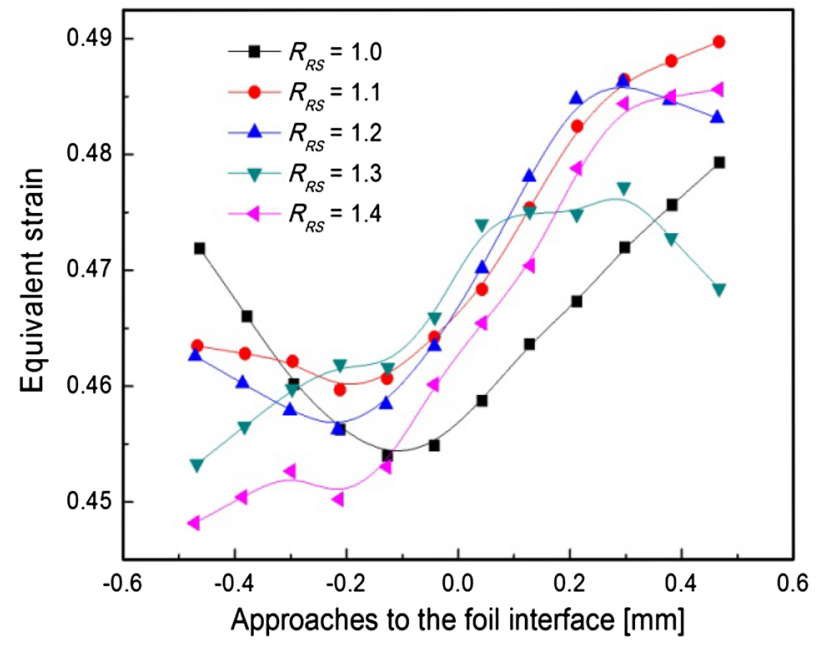

(a)

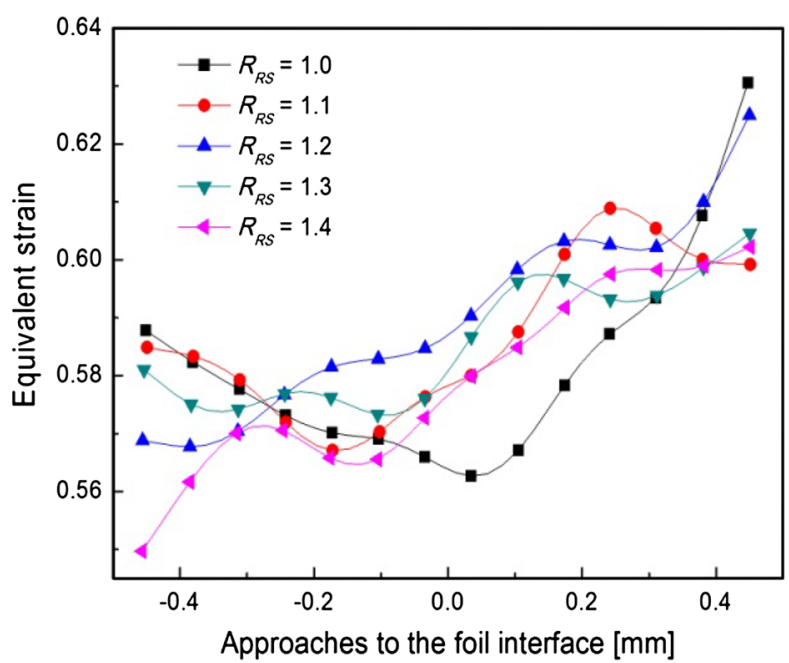

(b)

Fig. 6-Equivalent strain distribution at the exit of deformation zone under various speed ratios of upper and lower rolls, (a) reduction ratio 30 pct, (b) reduction ratio 40 pct.

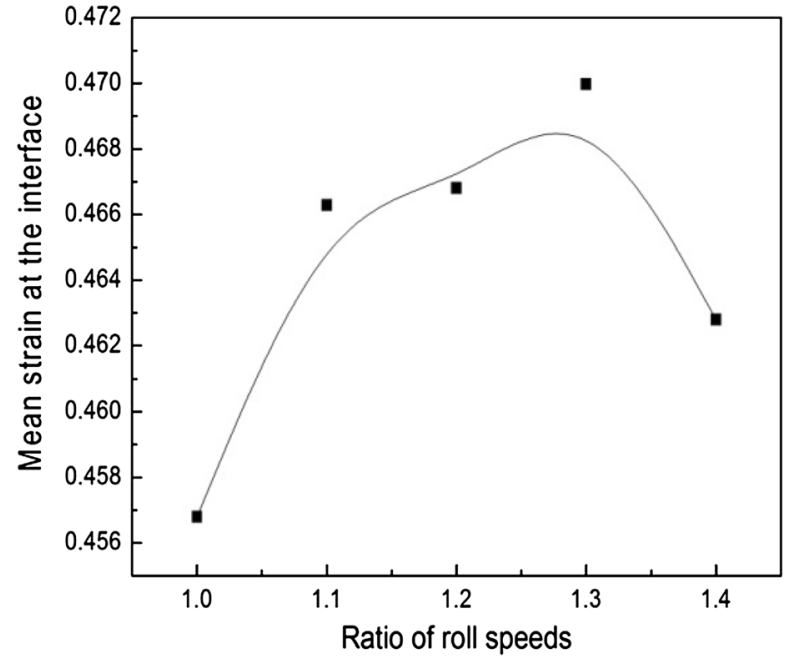

(a)

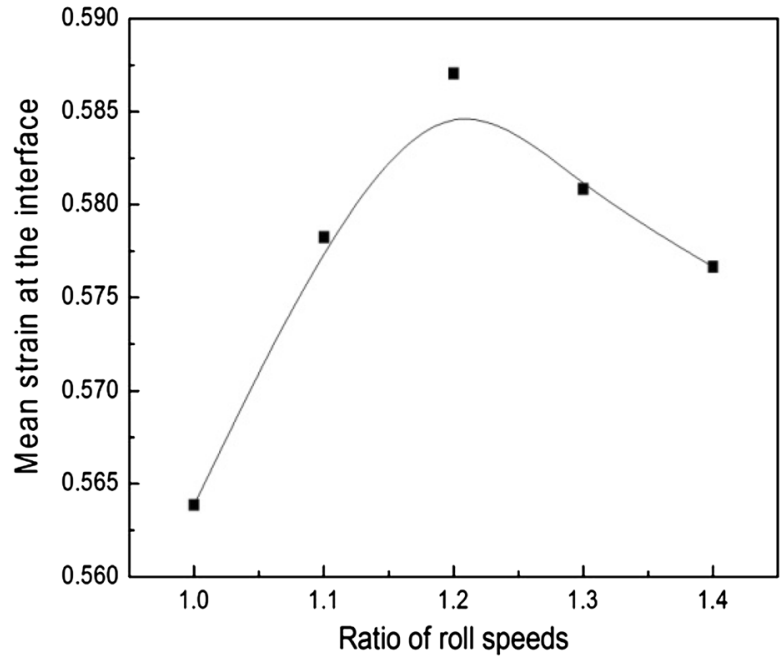

(b)

Fig. 7-Equivalent strain at interface under various ratios of rolls speed, (a) reduction ratio 30 pct, (b) reduction ratio 40 pct.

which is more complex compared to that in Figure 1. With progressively higher speed ratio, the minimum position of the interface shifts gradually toward the exit position, and they gradually come back to the initial position. It is not difficult to understand that the greater is the minimum position to the exit position, and the equivalent strain at the interface will increase.

Figures 6(a) and (b) show the equivalent strain distribution in the foil section after rolling with different ratios of roll speeds, for a reduction ratio of 30 and 40 pct, respectively. When the speeds of upper and lower rolls are the same, the equivalent strain at most positions is lower than that following $\mathrm{AR}$, and the strain distribution in the section is not uniform. With increasing roll speed ratio, the strain distribution becomes more uniform. When the roll speed ratio reaches 1.2 and 1.3 , the equivalent strain in sheet attains a maximum, and the strain distribution is uniform, while for the roll speed ratio of 1.4 , the equivalent strain is reduced.

Figures 7(a) and (b) show the equivalent strain at the interface between the AA1050 layer and the AA6061 layer after rolling with different ratios of roll speeds, for a reduction ratio of 30 and 40 pct, respectively. In the figure, the equivalent strain increases with roll speed ratios up to 1.2 and 1.3 , where it attains the highest value. When the roll speed ratio is 1.4 , the equivalent strain at the interface diminishes. According to Eq. [6], ${ }^{[27]}$ the higher the equivalent strain at the interface, the stronger is the bonding of the interface, which is in good agreement with the experimental observations in Figures 3 and 4. 


\section{CONCLUSIONS}

1. A no. of residual voids are seen at the interface of AA1050/AA6061 bimetallic samples following one ARB pass. These gradually reduce in no. with further thickness reduction by AR at room temperature.

2. TEM images show that the interface quality is the best when the roll speed ratio is 1.2. There are no noticeable residual voids at the interface of the AA1050/AA6061 bimetallic foils for this ratio, however, residual voids are observed when the roll speed ratio is 1.0 or 1.4 .

3. The deformation of bimetallic sheets during asymmetric rolling under various roll speed ratios was simulated with finite element methods. The mean equivalent strain at the AA1050/AA6061 interface zone reaches a peak value for roll speed ratios of 1.2 and 1.3, which results in the best interface bond during AR processing of AA1050/AA6061 bimetallic foils. The bond strength model proposed by Govindaraj et al ${ }^{[27]}$ is consistent with this observation.

4. The best bond during AR is obtained at an optimum roll speed ratio of 1.2 , where the interface between the AA1050 and AA6061 shows no residual voids at the interface.

5. The shear angle $\theta$, which is controlled by the process parameters such as roll diameter, roll speed, and difference in friction between the upper and lower rolls, affects bond strength due to its direct relationship with equivalent strain. The equivalent strain is the greatest at a roll speed ratio of 1.2 leading to a uniform strain distribution and a stronger bond, and decreases when the ratio increases to 1.4.

\section{ACKNOWLEDGMENTS}

The lead author gratefully acknowledges the financial support from the Vice-Chancellor's Fellowship Grant and URC Small Grant at the University of Wollongong, and from the National Natural Science Foundation of China through Grant 51105071.

\section{REFERENCES}

1. A. Atrian and F. Fereshteh-Saniee: Comp. Part B, 2013, vol. 47, pp. $75-81$.
2. L. Zhang, L. Meng, S.P. Zhou, and F.T. Yang: Mater. Sci. Eng. A, 2004, vol. 371, pp. 65-71.

3. M.Z. Quadir, O. Al-Buhamad, L. Bassman, and M. Ferry: Acta Mater., 2007, vol. 55, pp. 5438-48.

4. L. Su, C. Lu, K. Tieu, G. Deng, and X. Sun: Rev. Adv. Mater. Sci., 2013, vol. 33, pp. 33-7.

5. K. Wu, H. Chang, E. Maawad, W. Gan, H. Brokmeier, and M. Zheng: Mater. Sci. Eng. A, 2010, vol. 527, pp. 3073-8.

6. X.B. Li, G.Y. Zu, M.M. Ding, Y.L. Mu, and P. Wang: Mater. Sci. Eng. A, 2011, vol. 529, pp. 485-91.

7. N. Kamikawa, T. Sakai, and N. Tsuji: Acta Mater., 2007, vol. 55, pp. $5873-88$.

8. V.M. Segal: Mater. Sci. Eng. A, 2002, vol. 338, pp. 331-44.

9. L.E. Murr, E.A. Trillo, S. Pappu, and C. Kennedy: J. Mater. Sci., 2002, vol. 37, pp. 3337-60.

10. A. Gholinia, P.B. Prangnell, and M.V. Markushev: Acta Mater., 2000, vol. 48, pp. 1115-30.

11. G.Y. Deng, C. Lu, L.H. Su, A.K. Tieu, H.L. Yu, and X.H. Liu: Comput. Mater. Sci., 2013, vol. 74, pp. 75-85.

12. E. Schafler and M.B. Kerber: Mater. Sci. Eng. A, 2007, vol. 462, pp. 139-43.

13. Y. Saito, H. Utsunomiya, N. Tsuji, and T. Sakai: Acta Mater., 1999, vol. 47, pp. 579-83.

14. S.H. Lee, Y. Saito, N. Tsuji, H. Utsunomiya, and T. Sakai: Scripta Mater., 2002, vol. 46, pp. 281-5.

15. H.L. Yu, C. Lu, K. Tieu, X.H. Liu, Y. Sun, Q.B. Yu, and C. Kong: Sci. Rep., 2012, vol. 2, Article 772.

16. H.L. Yu, A.K. Tieu, C. Lu, X.H. Liu, A. Godbole, and C. Kong: Mater. Sci. Eng. A, 2013, vol. 568, pp. 212-8.

17. A.I. Petrov and M.V. Razuvaeva: Phys. Solid State, 2005, vol. 47, pp. $907-13$.

18. H. Li, K. Nagai, and F.X. Yin: Sci. Technol. Adv. Mater., 2008, vol. 9, Article 023001.

19. R. Jammaati and M.R. Toroghinejad: Mater. Sci. Technol., 2011, vol. 27, pp. 1101-8.

20. X.B. Li, G.Y. Zu, and P. Wang: Mater. Sci. Eng. A, 2013, vol. 562, pp. 96-100.

21. H.L. Yu, C. Lu, K. Tieu, A. Godbole, L.H. Su, Y. Sun, M. Liu, D.L. Tang, and C. Kong: Sci. Rep., 2013, vol. 3, Article 2373.

22. L.R. Vaidyanath, M.G. Nicholas, and D.R. Milner: Br. Weld. J., 1959, vol. 6, pp. 13-28.

23. P.K. Wright, D.A. Snow, and C.K. Tay: Met. Technol., 1978, vol. 5 , pp. 24-31.

24. N. Bay, C. Clemensen, and O. Juelstorp: CIRP Ann. Manuf. Technol., 1985, vol. 34, pp. 221-4.

25. W. Zhang and N. Bay: CIRP Ann. Manuf. Technol., 1996, vol. 45, pp. 215-20.

26. H.R. Madaah-Hosseini and A.H. Kokabi: Mater. Sci. Eng. A, 2002, vol. 335, pp. 186-90.

27. N.V. Govindaraj, S. Lauvdal, and B. Holmedal: J. Mater. Process. Technol., 2013, vol. 213, pp. 955-60.

28. S.Z. Wang and L. Ou: Met. Mater. Metall. Eng., 2007, vol. 35, pp. 34-36.

29. K.M. Lee, C.D. Yeo, and A.A. Polycarou: J. Mater. Res., 2008, vol. 23, pp. 2229-37.

30. Q. Cui and K. Ohori: Mater. Sci. Technol., 2000, vol. 16, pp. 1095 1101 . 